\title{
Influence of Maternal Nutritional Status on Prenatal Growth in a Peruvian Urban Population
}

\author{
A. R. FRISANCHO, J. E. KLAYMAN ${ }^{1}$ aND JORGE MATOS ${ }^{2}$ \\ ${ }_{1}$ Center for Human Growth and Development and the Department of \\ Anthropology, University of Michigan, Ann Arbor, Michigan \\ 48109 and $^{2}$ the Maternity Hospital of Lima, Peru
}

\author{
KEY WORDS Maternal nutrition - Protein - Calorie P Prenatal \\ growth $\cdot$ Skinfold $\cdot$ Muscle $\cdot$ Peru
}

\begin{abstract}
Anthropometric measurements were made on 4,952 mothers and their neonates from a Peruvian urban population. Based on age-specific percentiles, the mothers were separated into categories of short and tall stature, high and low fat, and high and low muscle. The study indicates that: (1) tall and short mothers characterized by similar subcutaneous fat and upper arm muscle area (whether high or low) had newborns with similar birth weight and recumbent length; (2) mothers characterized by high subcutaneous fat had heavier and fatter, but not longer, newborns than mothers with low subcutaneous fat; (3) mothers characterized by high upper arm muscle area had heavier, leaner and longer newborns than mothers with low upper arm muscle area; (4) mothers characterized by high muscle and high fat had heavier and longer newborns than mothers with high muscle and low fat; but (5) mothers characterized by high muscle and low fat had heavier and longer newborns than mothers with low muscle and high fat. Considering that subcutaneous fat and arm muscle area reflect calorie and protein reserves respectively, it is concluded that an increase in maternal calorie reserves results in increased infant fatness, but a lesser increase in linear growth. In contrast, an increase in maternal protein reserves does enhance both birth weight and prenatal linear growth.
\end{abstract}

The hypothesis that the fetus is completely protected against maternal inadequacies is no longer tenable. As demonstrated by previous studies, variations in maternal nutritional status are associated with differences in the frequency of lower birth weights (Antonov, '47; Smith, '47; Weis and Jackson, '69; Weis et al., '69; National Academy of Sciences, '70; Rush et al., '72; Niswander and Gordon, '72; Sinclair and Saigal, '75; Lechtig et al., '75; Beisel, '75; Rush, '75). In various studies the amounts of subcutaneous fat and body muscle have been used as indications of the calorie and protein reserves present in the body (Waterlow and Mendes, '57; Standard et al., '59; Garn and Haskell, '59, '60; Garn, '62; Jelliffe, '66). The utility of these anthropometric measurements in evaluating human growth and nutritional status has been documented by various investigators (Stini, '69; Dugdale et al., '70; Frisancho and Baker, '70; Frisancho et al., ' 71 ; Frisancho and Garn, '7la,b; Johnston et al., '71; Anderson, '75). However, the possible relationship of maternal subcutaneous fat and muscle size to prenatal growth has not been documented (Rush, '75; Beisel, '75). Accordingly, in the present study of a Peruvian urban population, we have analyzed the relationship of maternal triceps skinfolds, upper arm muscle area, and stature to neonatal anthropometric measurements.

\section{METHODS AND MATERIALS}

In 1973 we conducted an anthropometric and demographic study of an urban Peruvian population from the city of Lima. The study included a total sample 
of 4,952 mothers and their neonates attended at the Maternity Hospital of Lima; these women represented $75 \%$ of the total population of mothers who gave birth at the hospital between July and December, 1973. The age of the mothers ranged from 13 to 40 years; their average number of years of schooling was about four. As indicated in a previous publication (Frisancho et al., '76), the average per capita income was about $\$ 229,63 \%$ of which was used for purchasing food. We chose the Maternity Hospital of Lima because it enabled us to obtain accurate information on reproductive characteristics.

\section{MEASUREMENTS}

\section{Maternal}

Measurements of height $(\mathrm{cm})$, pre-partum weight $(\mathrm{kg})$, upper arm circumference $(\mathrm{mm})$ and triceps skinfolds thickness $(\mathrm{mm})$ were obtained using standard procedures (Weiner and Lourie, '69). With the right arm hanging relaxed, the upper arm circumference was measured to the nearest millimeter midway between the tip of the acromion and the olecranon process using a steel tape. The triceps skinfold thickness was also measured to the nearest millimeter with the right arm hanging freely, at the same point on the back of the arm, using a Lange skinfold caliper having a pressure of $10 \mathrm{~g} / \mathrm{mm}$ on the contact surface area. All the maternal measurements were taken upon admittance to the hospital and prior to delivery.

\section{Neonatal}

Measurements of birth weight (gm), recumbent length $(\mathrm{cm})$, head circumference $(\mathrm{cm})$, thorax circumference $(\mathrm{cm})$, upper arm circumference $(\mathrm{mm})$ and triceps skinfold thickness $(\mathrm{mm})$ were obtained through standard procedures (Faulkner, '60) and taken within six hours of delivery. The means and standard deviations by sex are given in table 1 , as well as the general characteristics of the mothers. These data show that with the exception of gestational age, the mean values for males are significantly greater than those for females in all measurements. For this reason the data are analyzed separately by sex.

Both the maternal and neonatal information were obtained by an obstetrician, a pediatrician and nurses properly trained by the authors (A. R. F. and J. M.). Great care was taken to ensure the reliability of this information by weekly monitoring and rechecking of the actual measurements.

\section{Estimates of muscle size}

Using the measurements of upper arm circumference and triceps skinfold thickness, the maternal and neonatal upper arm muscle areas $\left(\mathrm{mm}^{2}\right)$ were calculated as follows, using the procedures and restrictions as defined by Frisancho ('74):

upper arm muscle area $\left(\mathrm{mm}^{2}\right)=\frac{\pi}{4}$

(upper arm muscle diameter $\mathrm{mm}^{2}$,

where

$$
\begin{aligned}
& \text { upper arm muscle diameter }(\mathrm{mm})= \\
& \frac{\text { upper arm circumference }(\mathrm{mm})}{\pi}- \\
& \text { triceps skinfold }(\mathrm{mm}) \text {. }
\end{aligned}
$$

\section{Indices of nutritional status}

Based on measurements of triceps skinfolds, upper arm muscle area, and stature, two sub-groups each of fatness, muscle and stature were selected from the total sample of 4,952 women. The stature groups included:

(a) 1056 short subjects $($ mean $=146.8$ $\mathrm{cm} \pm 2.3 \mathrm{~cm})$

(b) 670 tall subjects (mean $=158.9 \mathrm{~cm}$ $\pm 3.5 \mathrm{~cm}$ )

The fatness groups included:

(a) 1144 lean subjects (triceps mean $=$ $8.4 \mathrm{~mm} \pm 1.7 \mathrm{~mm}$ )

(b) 806 fat subjects (triceps mean = $23.2 \mathrm{~mm} \pm 3.8 \mathrm{~mm}$ )

The muscle groups included:

(a) 948 low-muscled subjects (mean = $2281.5 \mathrm{~mm}^{2} \pm 212.0 \mathrm{~mm}^{2}$ )

(b) 930 high-muscled subjects (mean = $4225.7 \mathrm{~mm}^{2} \pm 596.6 \mathrm{~mm}^{2}$ )

Age-specific percentiles for stature, triceps skinfolds and upper arm muscle area were calculated in order to define these six 
TABLE $I$

Comparison of neonatal characteristics by sex and general characteristics of mothers from a Peruvian urban population

\begin{tabular}{|c|c|c|c|c|c|c|c|}
\hline \multirow{2}{*}{ Variable } & \multicolumn{3}{|c|}{ Male } & \multicolumn{3}{|c|}{ Female } & \multirow[b]{2}{*}{$t$} \\
\hline & $\mathbf{N}$ & Mean & S.D. & $\mathbf{N}$ & Mean & S.D. & \\
\hline Gestation age (wks) & 2108 & 39.1 & 2.0 & 2046 & 39.2 & 2.0 & 1.61 \\
\hline Birthweight (g) & 2439 & 3383.3 & 489.5 & 2348 & 3282.5 & 449.0 & $7.21^{2}$ \\
\hline Recumbent length (cm) & 2333 & 49.8 & 2.0 & 2258 & 49.4 & 1.9 & $6.95^{2}$ \\
\hline Head circumference $(\mathrm{cm})$ & 2354 & 34.4 & 1.5 & 2285 & 34.1 & 1.5 & $9.08^{2}$ \\
\hline Thorax circumference $(\mathrm{cm}\}$ & 2351 & 3.3 .7 & 1.7 & 2281 & 33.3 & 1.7 & $8.01^{2}$ \\
\hline Right arm circumference (mm) & 2354 & 108.5 & 13.0 & 2282 & 106.6 & 12.8 & $5.28^{2}$ \\
\hline Skinfold thickness (mm) & 2350 & 6.3 & 2.9 & 2277 & 6.0 & 2.8 & $3.58^{2}$ \\
\hline \multirow[t]{3}{*}{ Muscle area $\left(\mathrm{mm}^{2}\right)$} & 2348 & 640.7 & 194.4 & 2276 & 628.4 & 192.4 & $2.16^{3}$ \\
\hline & & & \multicolumn{5}{|c|}{ Mothers } \\
\hline & & & $\mathrm{N}$ & & Mean & & S.D. \\
\hline Age (years) & & & 4775 & & 24.10 & & 6.10 \\
\hline Height (cm) & & & 4481 & & 151.70 & & 4.30 \\
\hline Prepartum weight $(\mathrm{kg})$ & & & 2474 & & 62.70 & & 7.20 \\
\hline Arm muscle area $\left(\mathrm{mm}^{2}\right)$ & & & 4712 & & 3172.60 & & 737.58 \\
\hline Triceps skinfolds (mm) & & & 4723 & & $\mathrm{I} 4.80$ & & 5.40 \\
\hline Per capita income $(\$)^{3}$ & & & 2817 & & 230.30 & & 170.05 \\
\hline Per capita food expense $(\$)^{1}$ & & & 2998 & & 145.04 & & 68.09 \\
\hline Education (years) & & & 4403 & & 4.10 & & 2.80 \\
\hline
\end{tabular}

${ }_{1}^{1}$ Per capita income and per capita food expense were calculated by family units, excluding in each family children whose age exceeded 25 years.

${ }^{2} \mathrm{p}<0.001$.

${ }^{3} \mathrm{p}<0.05$.

groups. Then, on the basis of this information the subjects were classified as either lean or fat, low-muscled or high-muscled, and short or tall, depending on whether their triceps skinfolds, upper arm muscle area and stature were less than the twentieth or greater than the eightieth age-specific percentiles for these respective measurements.

Subsequently, subjects were also classified as either short-lean or tall-lean, either short-low muscle or tall-low muscle, either short-fat or tall-fat, and either short-high muscle or tall-high muscle. In addition, they were also grouped as either high muscle-high fat, high muscle-low fat or low muscle-high fat.

We have analyzed the data by 5-year intervals for maternal age groups so as to control for the influence of increasing maternal age. Observations of neonatal characteristics by parity showed no major variations. Furthermore, as indicated in the present study, because birth weight and recumbent length increase with maternal age up to 40 years, we have compared these groups for statistical differences by analyses of covariance as well. Here the mean birth weights and recumbent lengths are compared with respect to an equal, projected maternal age; in this manner, possible variations in maternal age are not reflected in the comparisons of the neonatal measurements.

Finally, due to space limitations the present study considers only evaluations of birth weight, recumbent length, triceps skinfolds and upper arm muscle area. For the same reason, the different maternal categories are compared graphically on the basis of the mean \pm standard error of the mean. All inferences regarding statistical significance are based on Student ttests or analysis of covariance.

\section{RESULTS AND DISCUSSION Stature}

As shown in figure 1, although the male 

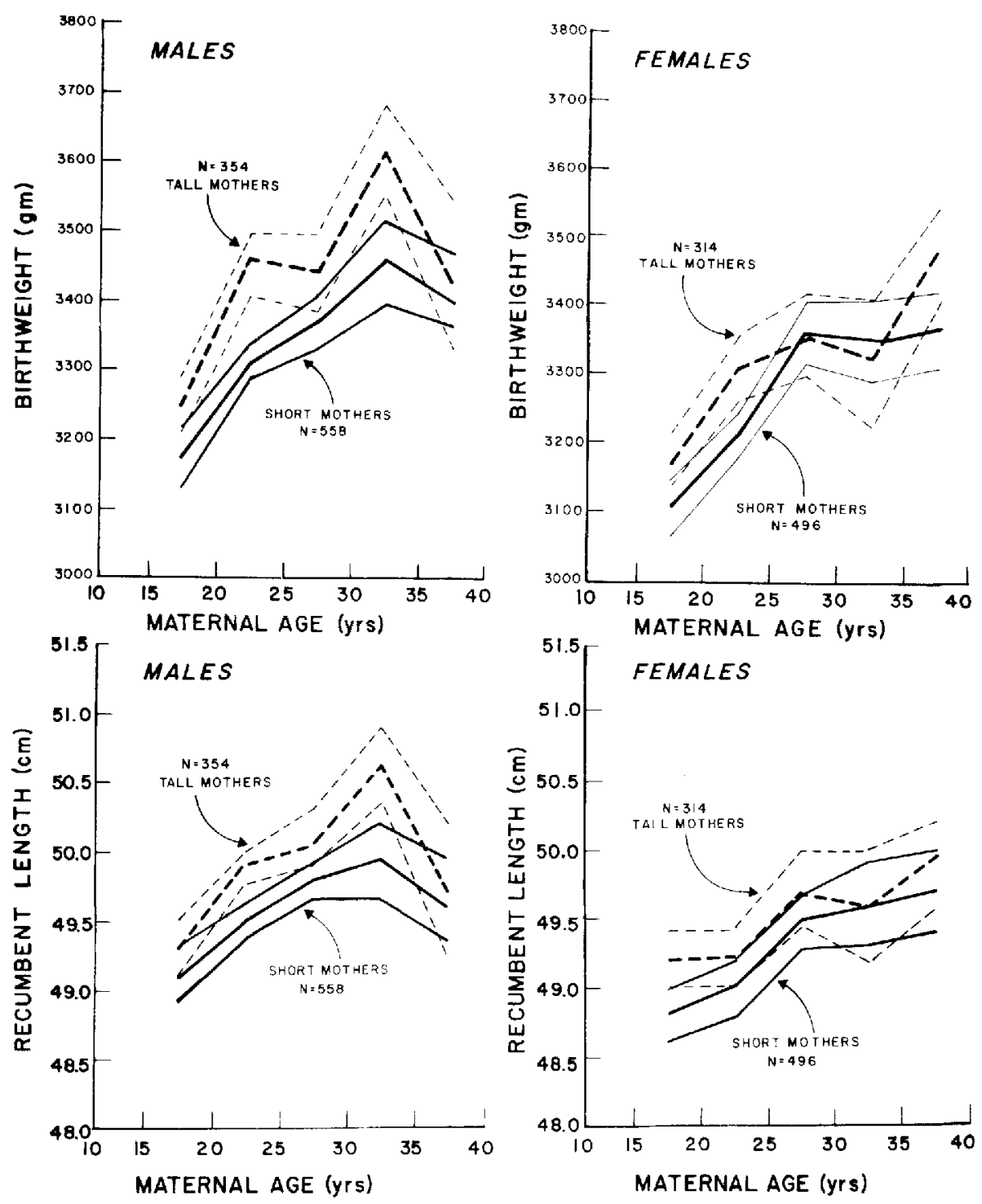

Fig. 1 Relationship of birth weight and recumbent length to maternal age by maternal height categories. Note that differences in maternal stature are not associated with differences in prenatal growth.

newborns of tall mothers tend to be heavier and longer than those of short mothers, these differences do not reach statistical significance. Similarly, the female newborns of tall mothers have comparable birth weights and recumbent lengths to those of short mothers.

\section{Skinfolds}

From figure 2 it is quite evident that fat mothers have significantly $(\mathrm{p}<0.05$ to $\mathrm{p}<$ 0.001) fatter newborns, i.e., having a greater triceps skinfold thickness, than lean mothers, but fat mothers do not necessarily produce longer newborns, i.e., having a greater recumbent length, than do lean mothers.

\section{Upper arm muscle}

Figure 3 demonstrates that male new- 

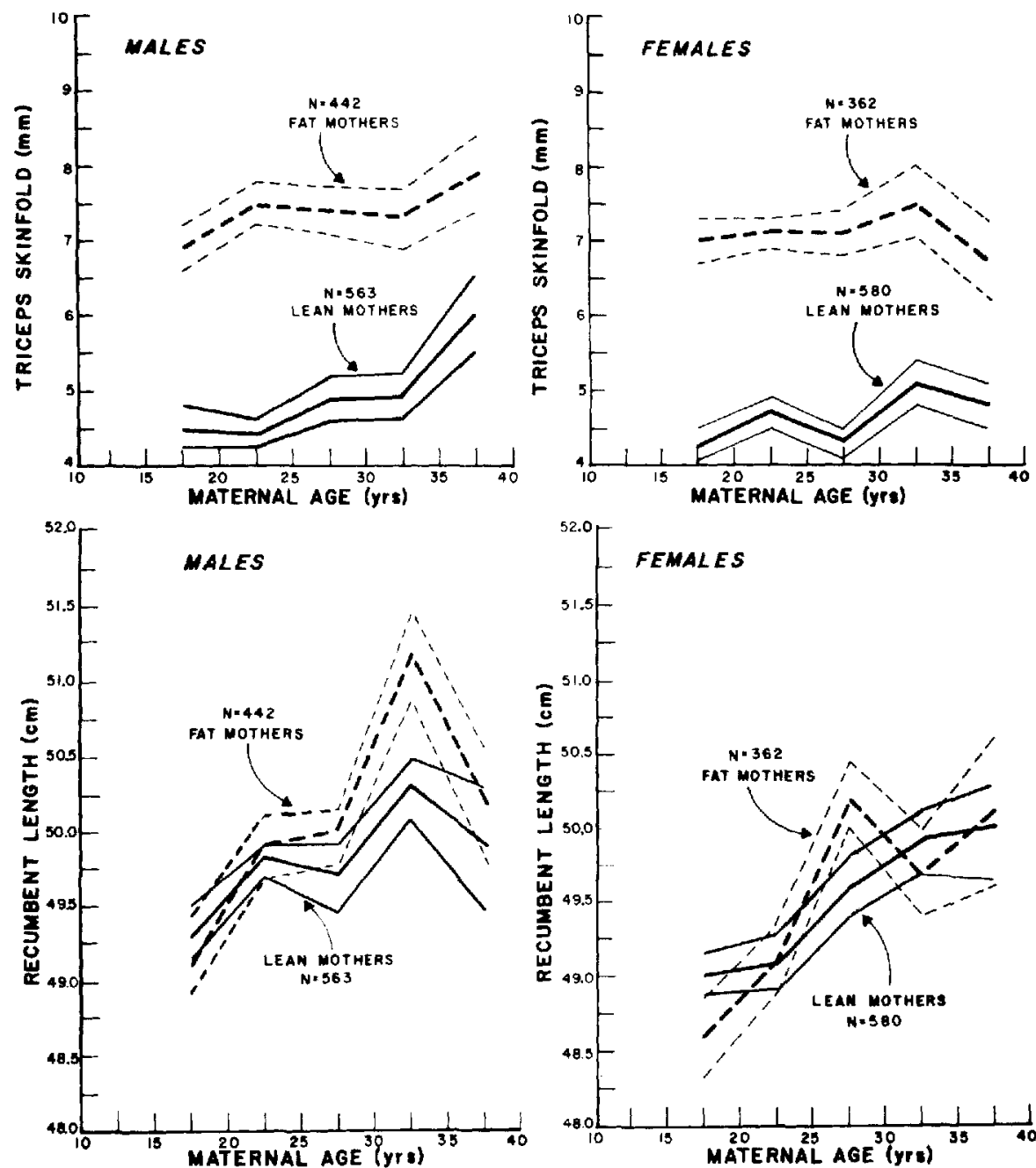

Fig. 2 Relationship of neonatal triceps skinfolds and recumbent length to maternal age by maternal fatness categories. Although fat mothers have fatter newborns, they do not necessarily have longer newborns when compared to lean mothers.

borns of more muscular mothers have significantly $(p<0.01)$ greater muscle area than those of less muscular mothers. The more muscular mothers also have significantly $(p<0.01)$ longer newborns except in the 30 to 34-year age group. Among female newborns, those of more muscular mothers have significantly ( $p<0.01$ ) greater muscle area than those of less muscular mothers. However, in terms of recumbent length the differences are not systematic. For example, there are no major differences in female newborns' recum- bent length within maternal age groups 20-24 years and 25-29 years. At other age groups (13-19 years, $30-34$ years and 35-39 years) high-muscled mothers have significantly $(\mathrm{p}<0.05)$ longer newborns than do low-muscled mothers.

Several investigators have shown that positive variations in skinfold thickness during growth are associated with advanced dimensional growth and advanced maturation (Talbot, ' 45 ; Reynolds, ' 46 , '50; Fry, '53; Peckos, '53; Quaade, '55; Wolff, '55; Garn and Haskell, '60; Lloyd et al., 

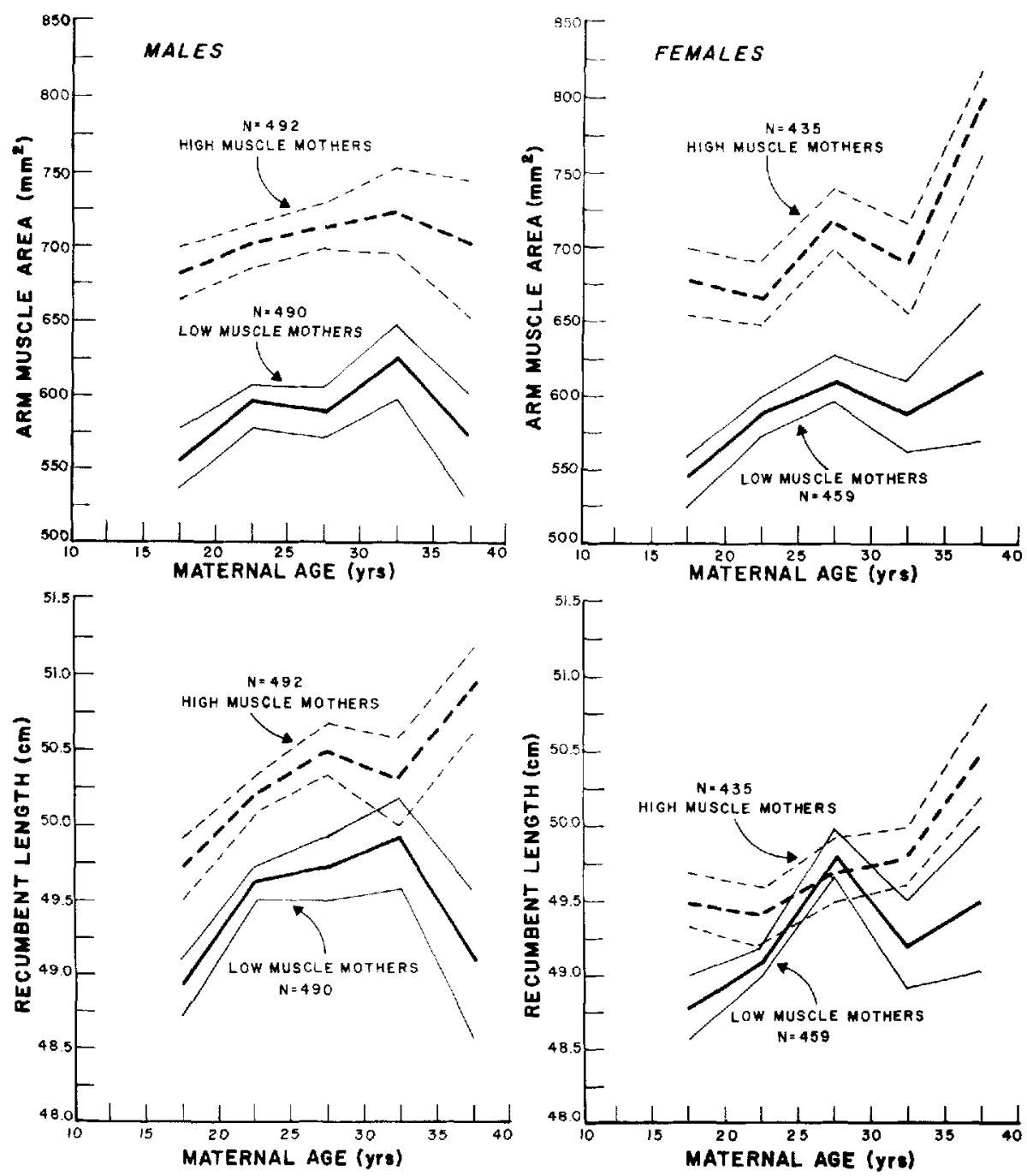

Fig. 3 Relationship of neonatal upper arm muscle area and recumbent length to maternal age by maternal muscularity categories. Mothers with high muscle have more muscular and longer male newborns than do mothers with low muscularity.

'61). This association suggests that increased subcutaneous fat, resulting from either high calorie intake or low energy expenditure, reflects a greater amount of calorie reserves. On the other hand, experimental and clinical studies have shown that the decrease in infant muscle mass under conditions of malnutrition is greater than the reduction in body weight (Waterlow and Mendes, '57; Standard et al., '59). This reduction in muscle mass occurs as a compensatory mechanism to provide ade- quate amino acids for gluconeogenesis and protein synthesis in the liver (Arroyave and Castellanos, '61). The existence of such a mechanism suggests that if skeletal muscularization is well maintained, then the protein requirements for growth and maintenance of body tissues have been met. In other words, the size of the body muscle is indicative of the level of protein reserves. This is supported by analyses of Central American and Asiatic samples, which indicate that during growth, greater 
muscularity is associated with greater stature, thus demonstrating that measurements of muscularity do serve as a general index of nutritional status and growth in size (Dugdale et al., '70; Frisancho and Garn, '7la,b; Frisancho et al., '71; Anderson, '75).

On the basis of these investigations, we would expect fat mothers to have greater calorie reserves than lean mothers. Similarly, more muscular mothers would be expected to have greater protein reserves than their less muscular counterparts. The present study indicates that increased maternal subcutaneous fat is reflected in greater infant fatness, but is not associated with significantly greater birth weight or recumbent length. This suggests that increased maternal calorie reserves are not reflected in greater linear growth. On the other hand, increased maternal arm muscle area is associated with significantly greater arm muscle area and recumbent length, especially in male newborns. Thus increased maternal protein reserves are ap- parently directly reflected in enhanced prenatal growth and greater protein reserves.

\section{Stature, skinfolds and arm muscle}

Table 2 compares the birth weight and recumbent length in newborns of mothers with low and high triceps skinfold thicknesses. These data show that short and tall mothers with low fatness have newborns with similar birth weights and recumbent lengths. In the same manner, short and tall fat mothers have newborns with similar birth weights and recumbent lengths, although in males tall mothers do have slightly heavier newborns $(\mathrm{p}<0.05)$.

From table 2 it is also evident that short and tall mothers characterized by low muscle area have newborns with similar birth weights and recumbent lengths. Furthermore, short and tall mothers with high muscle area have newborns with equivalent birth weights and recumbent lengths. Thus it appears that when either protein (muscle) or calorie (fat) reserves are con-

TABLE 2

Comparison of birth weight and recumbent length by maternal stature with low and high triceps skinfold and upper arm muscle in a Peruvian urban population

\begin{tabular}{|c|c|c|c|c|c|c|c|c|c|c|c|c|}
\hline \multirow{2}{*}{$\begin{array}{l}\text { Maternal fat-muscle } \\
\text { categories }\end{array}$} & \multicolumn{6}{|c|}{ Birth weight (gm) } & \multicolumn{6}{|c|}{ Recumbent length (cm) } \\
\hline & $\mathrm{N}$ & Mean & S.D. & $\begin{array}{c}\text { Contrast } \\
\text { groups }\end{array}$ & $t^{1}$ & $\mathrm{~F}^{2}$ & $\mathrm{~N}$ & Mean & S.D. & $\begin{array}{c}\text { Contrast } \\
\text { groups }\end{array}$ & $t^{1}$ & $\mathbf{F}^{2}$ \\
\hline \multicolumn{13}{|c|}{ Males } \\
\hline (1) Short-lean & 78 & 3298.5 & 432.5 & 1 vs 2 & 0.71 & 0.57 & 78 & 49.4 & 2.0 & 1 vs 2 & 1.53 & 3.41 \\
\hline (2) Tall-lean & 85 & 3349.4 & 496.7 & 3 vs 4 & 1.86 & $4.18^{3}$ & 85 & 49.9 & 2.0 & 3 vs 4 & 1.38 & 2.08 \\
\hline (3) Short-fat & 108 & 3353.6 & 485.4 & & & & 108 & 49.6 & 1.9 & & & \\
\hline (4) Tall-fat & 89 & 3463.0 & 477.1 & & & & 89 & 50.0 & 2.1 & & & \\
\hline (5) Short-low muscle & 170 & 3289.9 & 459.5 & 5 vs 6 & 0.15 & 0.03 & 170 & 49.4 & 2.0 & 5 vs 6 & 0.62 & 0.16 \\
\hline (6) Tall-low muscle & 41 & 3301.5 & 526.2 & 7 vs 8 & 1.19 & 2.27 & 41 & 49.6 & 2.3 & 7 vs 8 & 1.80 & 2.59 \\
\hline (7) Short-high muscle & 36 & 3375.3 & 463.7 & & & & 36 & 49.6 & 2.1 & & & \\
\hline (8) Tall-high muscle & 87 & 3492.0 & 510.7 & & & & 87 & 50.3 & 1.6 & & & \\
\hline \multicolumn{13}{|c|}{ Females } \\
\hline (1) Short-lean & 65 & 3224.4 & 391.7 & 1 vs 2 & 0.18 & 0.03 & 65 & 49.1 & 2.0 & 1 vs 2 & 0.33 & 0.01 \\
\hline (2) Tall-lean & 75 & 3210.8 & 521.4 & 3 vs 4 & 0.92 & 0.06 & 75 & 49.0 & 2.4 & 3 vs 4 & 0.07 & 1.00 \\
\hline (3) Short-fat & 86 & 3347.7 & 497.3 & & & & 86 & 49.3 & 2.1 & & & \\
\hline (4) Tall-fat & 53 & 3267.8 & 514.5 & & & & 53 & 49.3 & 2.2 & & & \\
\hline (5) Short-low muscle & 155 & 3200.6 & 496.6 & 5 vs 6 & 0.40 & 0.16 & 155 & 49.2 & 2.0 & 5 vs 6 & 0.79 & 1.55 \\
\hline (6) Tall-low muscle & 27 & 3241.0 & 526.2 & 7 vs 8 & 0.53 & 1.31 & 27 & 48.9 & 2.3 & 7 vs 8 & 1.81 & 2.73 \\
\hline (7) Short-high muscle & 24 & 3231.7 & 442.3 & & & & 24 & 48.5 & 2.8 & & & \\
\hline (8) Tall-high muscle & 90 & 3285.6 & 450.6 & & & & 90 & 49.4 & 2.0 & & & \\
\hline
\end{tabular}

${ }^{1}$ T-test calculated without adjusting for possible differences in maternal age.

2 F-test calculated by a one-way analysis of covariance, whereby the mean values are compared at equal predicted maternal ages isee textl.

${ }^{3} \mathrm{p}<0.05$. 
stant (whether equally high or low), differences in maternal stature have minimal relationship to prenatal growth.

The lack of association between maternal stature and neonatal measurements in the present study suggests that variations in stature alone have minimal effects on prenatal growth. Recent studies among U.S. poor and medium income populations also indicate that maternal height, corrected for pre-pregnancy weight and weight gain, has only a negligible relationship to birth weight (Weis and Jackson, '69; Weis et al., '69; Rush et al., '72).

\section{Skinfolds and arm muscle}

Table 3 compares the birth weights and recumbent lengths of newborns by maternal muscle-fatness groups. From these data the following points are evident: (a) when both maternal protein and calorie reserves are increased (high muscle and high fat), birth weight and recumbent length in males are significantly $(\mathrm{p}<0.05$ ) greater when compared to those cases where only maternal protein (high muscle and low fat) or calorie (low muscle and high fat) reserves are increased; (b) in females, when both maternal protein and calorie reserves are increased (high muscle and high fat), birth weight and recumbent length are significantly greater ( $p<0.05$ to $p<0.01$ ) when compared to those in situations where only the calorie reserves are increased (low muscle and high fat), whereas there are only small differences in prenatal growth when compared to those cases where only protein reserves are increased (high muscle and low fat); (c) in both sexes birth weight and recumbent length are significantly $(\mathrm{p}<0.01)$ greater among newborns of mothers with high protein reserves (high muscle and low fat) than among those of mothers with high calorie reserves (low muscle and high fat). These findings together suggest that an increase in maternal calorie reserves, unless accompanied by a corresponding increase in maternal protein reserves, may increase neonatal subcutaneous fat, but may not enhance linear growth. Improvement in linear growth requires an increase in both

TABLE 3

Comparison of birth weight and recumbent length by maternal muscle-fatness groups of a Peruvian urban sample matched for maternal age

\begin{tabular}{|c|c|c|c|c|c|c|c|c|c|c|c|}
\hline \multirow{2}{*}{$\begin{array}{l}\text { Maternal muscle- } \\
\text { fatness group }\end{array}$} & \multicolumn{6}{|c|}{ Birth weight (gm) } & \multicolumn{5}{|c|}{ Recumbent length $(\mathrm{cm})$} \\
\hline & $\mathrm{N}$ & Mean & S.D. & $\begin{array}{l}\text { Contrast } \\
\text { group }\end{array}$ & $t^{2}$ & $\mathrm{~F}^{1}$ & Mean & S.D. & $\begin{array}{l}\text { Contrast } \\
\text { group }\end{array}$ & $t^{2}$ & $\mathbf{F}^{1}$ \\
\hline \multicolumn{12}{|c|}{ Males } \\
\hline (1) High muscle & & & & & & & & & & & \\
\hline $\begin{array}{l}\text { High fat } \\
\text { (2) High muscle }\end{array}$ & 40 & 3666.6 & 515.0 & 1 vs 2 & $2.79^{4}$ & $5.71^{3}$ & 50.9 & 2.0 & 1 vs 2 & $2.07^{3}$ & $4.91^{3}$ \\
\hline $\begin{array}{l}\text { Low fat } \\
\text { (3) High fat }\end{array}$ & 206 & 3419.0 & 503.0 & 1 vs 3 & $3.75^{4}$ & $12.42^{4}$ & 50.2 & 1.7 & 1 vs 3 & $3.67^{4}$ & $10.23^{4}$ \\
\hline Low muscle & 131 & 3321.7 & 481.8 & 2 vs 3 & 1.76 & $5.25^{3}$ & 49.5 & 2.4 & 2 vs 3 & $2.86^{4}$ & $11.08^{4}$ \\
\hline & & & & & Female & & & & & & \\
\hline $\begin{array}{l}\text { (1) High muscle } \\
\text { High fat } \\
\text { (2) High muscle }\end{array}$ & 39 & 3491.8 & 489.0 & 1 vs 2 & 1.75 & 3.15 & 50.6 & 1.9 & 1 vs 2 & $2.90^{3}$ & 1.29 \\
\hline $\begin{array}{l}\text { Low fat } \\
\text { (3) High fat }\end{array}$ & 194 & 3337.9 & 457.5 & 1 vs 3 & $3.05^{4}$ & $9.74^{4}$ & 49.6 & 1.9 & 1 vs 3 & $4.32^{4}$ & $7.24^{4}$ \\
\hline Low muscle & 121 & 3210.9 & 467.8 & 2 vs 3 & $2.35^{3}$ & $7.12^{4}$ & 49.0 & 2.1 & 2 vs 3 & $2.55^{4}$ & $7.03^{4}$ \\
\hline
\end{tabular}

I F-statistic calculated by a one-way analysis of covariance, whereby the mean values are compared at equal predicted inaternal ages (see text).

2 T-test calculated without adjusting for possible differences in maternal age.

${ }^{3} \mathrm{p}<0.05$.

${ }^{4} p<0.01$. 
protein and calorie reserves. Moreover, variations in protein reserves appear to have a greater influence on prenatal growth than do variations in calorie reserves.

\section{CONCLUSIONS}

From this extensive study it is clear that maternal nutritional status during pregnancy has profound effects on prenatal growth. An important conclusion is also that differences in maternal stature appear to have minimal influence on birth weight and recumbent length when maternal protein and calorie reserves are held constant, as shown by the evaluations of triceps skinfolds and upper arm muscle area. In terms of calorie and protein reserves, the data suggest that an increase in maternal protein reserves (muscle) has a greater influence on linear growth than an increase in calorie reserves (fat). These conclusions, however, may not be applicable to populations characterized by chronic malnutrition. In a population suffering from chronic malnutrition an increase in calories alone may be reflected in a marked increase in prenatal growth, and in terms of energy metabolism, this would be an expected response.

\section{ACKNOWLEDGMENTS}

This study was supported in part by Grant GS-37542 X of the National Science Foundation and by research funds from the University of Michigan. The authors thank the mothers who participated in this study and the staff of the Maternity Hospital of Lima, Peru, without whom this study would not have been possible. We gratefully acknowledge the assistance of Ms. Donna Monroe in the preparation of this manuscript, and the assistance of Ms. Teryl Schessler in the preparation of illustrations.

\section{LITERATURE CITED}

Anderson, M. A. 1975 Use of height-arm circumference measurement for nutritional selectivity in Sri Lanka school feeding. Am. J. Clin. Nutr., 28: 775-781.

Antonov, A. N. 1947 Children born during the seige of Leningrad in 1942. J. Pediat., 30: 250-259.
Arroyave, G., and H. Castellanos 1961 Role of the adrenal cortical system in the response of children to severe protein malnutrition. Am. J. Clin. Nutr., 9: 186-195.

Beisel, W. R. 1975 Synergistic effects of maternal malnutrition and infection on the infant. Am. J. Dis. Child., 129: 571-574.

Dugdale, A. E, S. T. Chen and G. Hewitt 1970 Patterns of growth and nutrition in childhood. Am. J. Clin. Nutr., 23: 1280-1287.

Falkner, F. 1960 The somatic investigation. In: Modern Problems in Pediatrics. Vol. V. Child Development. F. Falkner, ed. S. Karger and Basel, New York.

Frisancho, A. R. 1974 Triceps skin fold and upper arm muscle size norms for assessment of nutritional status. Am. J. Clin. Nutr., 27: 1052-1058.

Frisancho, A. R, and P. T. Baker 1970 Altitude and Growth: A study of the patterns of physical growth of a high altitude Peruvian Quechua population. Am. J. Phys. Anthrop., 32: 279-292.

Frisancho, A. R., and S. M. Garn 1971a Skinfold thickness and muscle size: implications for developmental status and nutritional evaluation of children from Honduras. Am. J. Clin. Nutr., 24: 541-546.

1971b The implications of skinfolds and muscle size to developmental and nutritional status of Central American children, III: Guatemala. Trop. Geogr. Med., 23: 167-172.

Frisancho, A. R., S. M. Garn and L. D. McCreery 1971 Relationship of skinfolds and muscle size to growth of children. I. Costa Rica. Am. J. Phys. Anthrop., 35: 85-90.

Frisancho, A. R., J. E. Klayman and J. Matos 1976 Symbiotic relationship of high fertility, high childhood mortality and low socio-economic status in an urban Peruvian population. Hum. Biol., 48: 101-111.

Fry, P. C. 1953 A comparative study of "obese" children selected on the basis of fat pads. Am. J. Clin. Nutr., 1: 453-468.

Garn, S. M. 1962 Anthropornetry in clinical appraisal of nutritional status. Am. J. Clin. Nutr., 11:418-432. 1959 Fat and growth during childhood. Science, 130: 1711-1712.

Garn, S. M., and J. A. Haskell 1960 Fat thickness and developmental status in childhood and adolescence. Am. J. Dis. Child., 99: 746-751.

Jelliffe, D. B. 1966 The assessment of the nutritional status of the community. WHO Monograph, 53: 228.

Johnston, F. E., P. S. Gindhart, R. L. Jantz, K. M. Kensinger and G. F. Walker 1971 The anthropometric determination of body composition among the Peruvian Cashinahua. Am. J. Phys. Anthrop., 34: 409-416.

Lechtig, A., H. Delgado, R. E. Lasky, R. E, Klein, P. L. Engle, C. Yarbrough and J. P. Habicht 1975 Maternal nutrition and fetal growth in developing societies. Am. J. Dis. Child., 129: 434-436.

Lloyd, J. K., O. H. Wolff and W. S. Whelen 1961 
Childhood obesity: A longterm study of height and weight. Brit. Med. J., II: 145-148.

National Academy of Sciences 1970 Maternal Nutrition and the Course of Pregnancy. Committee on Maternal Nutrition, Food and Nutrition Board, National Research Council, Washington, D.C., pp. 110-138.

Niswander, K. R., and M. Gordon 1972 The Women and Their Pregnancies: The Collaborative Perinatal Study of the National Institute of Neurological Diseases and Stroke. W. B. Saunders Co., Philadelphia.

Peckos, P. S. 1953 Caloric intake in relation to physique in children. Science, 117; 631-633.

Quaade, F, 1955 Obese Children. Danish Science Press, Copenhagen.

Reynolds, E. L. 1946 Sexual maturation and the growth of fat, muscle and bone in girls. Child. Develop., 17: 121-144.

1950 The distribution of subcutaneous fat in childhood and adolescence. (Mon.) Soc. Res. Child Develop., 15: 189.

Rush, D. 1975 Maternal nutrition during pregnancy in industrialized societies. Am. J. Dis. Child, 129: 430-434.

Rush, D., H. Davis and M. W. Susser 1972 Antecedents of low birthweight in Harlem, New York City. Int. J. Epidemiol, 1: 375-387.

Sinclair, J. C., and S. Saigal 1975 Nutritional influences in industrial societies. Am. J. Dis. Child., 129: 549-553.
Smith, C. A. 1947 Effects of maternal undernutrition upon the newborn infant in Holland (1944-45). J Pediat., 30: 229-243.

Standard, K. L., V. G. Wills and J. C. Waterlow 1959 Indirect indicators of muscle mass in malnourished infants. Am. J. Clin. Nutr, 7: 271-279.

Stini, W. A. 1969 Nutritional stress and growth: sex difference in adaptive response. Am. J. Phys. Anthrop., 31: 417-426.

Talbot, N. B. 1945 Obesity in children. M. Clin. N. Amer., 29: 1217.

Waterlow, J. C., and C. B. Mendes 1957 Composition of muscle in malnourished human infants. Nature, 180: 1361-1362.

Weiner, J. S., and J. A. Lourie 1969 Human Biology: A Guide to Field Methods. Blackwell Scientific Publications, Oxford, England.

Weis, W., and E. C. Jackson 1969 Maternal factors affecting birthweight. In: Perinatal Factors Affecting Human Development. PAHO publication 185, Washington, D.C.

Weis, W., E. C. Jackson and K. R. Niswander 1969 The influence on birthweight of change in maternal weight gain in successive pregnancies in the same woman. Int. J. Gynecol. Obstet, 7: 210-223.

Wolff, O. H. 1955 Obesity in childhood: A study of the birth weight, the height and the onset of puberty. Quart. J. Med., 24: 109-123. 